\title{
An assessment of two extraordinary speed-readers
}

\author{
DONALD HOMA \\ Arizona State University, Tempe, Arizona 85257
}

\begin{abstract}
An assessment of perceptual and comprehension skills was made on two speed-readers from the American Speedreading Academy who had achieved extraordinary rates of reading. Three experiments were conducted: (1) measurement of perceptual extent for briefly exposed single letters, (2) identification of words within paragraphs under controlled viewing, and (3) text comprehension. The performance of the two speed-readers on the first two tasks was indistinguishable from that of normal readers, although both speed-readers exhibited greater guessing tendencies. On the text comprehension task, the speed-readers were given three opportunities to read a college text and receive an exam given to college students over the same material. Both speed-readers read the text at rates between 15,000 and 30,000 words $/ \mathrm{min}$. However, both speed-readers would have failed the exam on each occasion. It was concluded that the only extraordinary talent exhibited by the two speed-readers was their extraordinary rate of pageturning.
\end{abstract}

The present study investigated the perceptual and comprehension abilities of two young males who had achieved extraordinary rates of reading, according to officials of the American Speedreading Academy (ASA). ${ }^{1}$ Officials of the ASA claimed that both men read at rates exceeding 100,000 words/min (wpm), a rate unusual even in their program. Typically, people enrolled in their program achieve rates of $5,000-10,000 \mathrm{wpm}$, a rate comparable to that reported by other speed-reading agencies (e.g., Evelyn Wood's Reading Dynamics Program; Reed, 1982). Since the average reading rate for adults is about $300 \mathrm{wpm}$ (Gibson \& Levin, 1975), the current popularity of speed-reading programs is understandable.

Most researchers of reading are highly skeptical of speed-reading claims, arguing that the anatomy of the eye limits reading rates to a maximum of 900 $1,000 \mathrm{wpm}$. For example, perceptual detail is degraded at even $1 \mathrm{deg}$ of visual angle from the fixation point (e.g., Haber \& Hershenson, 1980). An individual who reads $10,000 \mathrm{wpm}$ would spend about $2.5 \mathrm{sec}$ per page of text. With three eye fixations per second, this rate would require that each fixation encompass about 55 words. Since 1 deg of visual angle roughly encompasses four or five letters of text read at a normal viewing distance, about $95 \%$ of these words would fall outside $1 \mathrm{deg}$ of visual angle. However, many speed-reading programs, including the ASA, claim that an individual can be trained to extend substantially the visual field during reading.

I would like to thank Julie Omohundro for collecting the data on the paragraph perception task. Requests for reprints should be sent to Donald Homa, Department of Psychology, Arizona State University, Tempe, Arizona 85257.
I was contacted by officials of the ASA, who suggested it should be possible to document the abilities of their two extraordinary speed-readers under laboratorycontrolled circumstances. I met with officials of the ASA on two occasions, during which we discussed a variety of tasks. The tasks finally selected were intended to sample a continuum of perceptual/cognitive skills and were judged as fair by officials of the ASA. These tasks were: (1) measurement of perceptual extent for single letters, (2) identification of words within paragraphs, and (3) text comprehension. The first two tasks involved brief visual presentations $(70 \mathrm{msec}$ for perceptual extent; 200, 500, and $800 \mathrm{msec}$ for paragraph presentation) and included normal readers as control subjects. For the text comprehension task, the two speed-readers read Roberta Klatzky's (1975) Human Memory text and then answered a multiple-choice exam. I had recently used the Klatzky text in a human memory course. In this class, students received a multiplechoice exam on the Klatzky text and short-answer questions on the lecture material and outside readings. The exam given to the speed-readers was identical to that received by students in the class.

Although the multiple-choice questions were taken directly from the Klatzky (1975) text, this task is probably biased, to an unknown degree, against the two speed-readers. In particular, the lectures may have reiterated portions of the Klatzky text that were tested on the multiple-choice exam. Furthermore, students read the text within the context of a human memory course. $^{2}$ Nonetheless, officials of the ASA were eager to see how well the two speed-readers would do with a college text, since one of the aims of the academy is to promote reading skills that would be valuable in college.

To partially offset the disadvantage of the speed- 
readers on the text comprehension task, each speedreader was given three opportunities to read the Klatzky (1975) text, with 3-5 days intervening between each reading. Following each reading, they received the identical exam, with ony the ordering of questions changed for each test.

\section{METHOD}

\section{Perceptual Extent}

Procedure. The subject was told to fixate a center dot $(1,000 \mathrm{msec})$ and to attempt identification of a single displaced letter $(70 \mathrm{msec})$. The subject was instructed to maintain fixation on the center dot and to avoid any eye movement during the trial. The displaced targets were drawn from a pool of eight letters (B, D, E, G, H, L, O, T). These letters appeared equally often and occurrred at 1 of 40 locations within the visual field. The 40 locations were determined by five distances on each of eight axes. The five distances were about .5, 1, 1.5, 2, and $2.5 \mathrm{deg}$ of visual angle from the fixation point. The eight axes were determined by four equally spaced lines passing through the fixation point. Figure 1 shows a reasonable facsimile of the grid containing the 40 locations. A copy of the grid was available to the subject throughout the session. It was fully explained that a displaced letter could appear at any of the $\mathbf{4 0}$ locations.

Following instructions, the subject was allowed to dark adapt for about $5 \mathrm{~min}$. Each subject received a couple of practice trials at $500 \mathrm{msec}$, followed by an additional 20 practice trials at $100 \mathrm{msec}$. If the subject had no further questions, the exposure duration was decreased to $70 \mathrm{msec}$ and maintained at that duration for all experimental trials.

On each trial, the signal "ready" was given. About $1 \mathrm{sec}$ later, a fixation point appeared $(1,000 \mathrm{msec})$, followed by the letter target $(70 \mathrm{msec})$; following offset of the target, a visual noise mask appeared $(500 \mathrm{msec})$. The subject then verbally reported the identity of the displaced letter, guessing from the pool of eight letters if necessary. A total of 80 trials occurred in a session. Each axis by distance combination occurred exactly twice in the 80 trials, and each of the eight target letters appeared

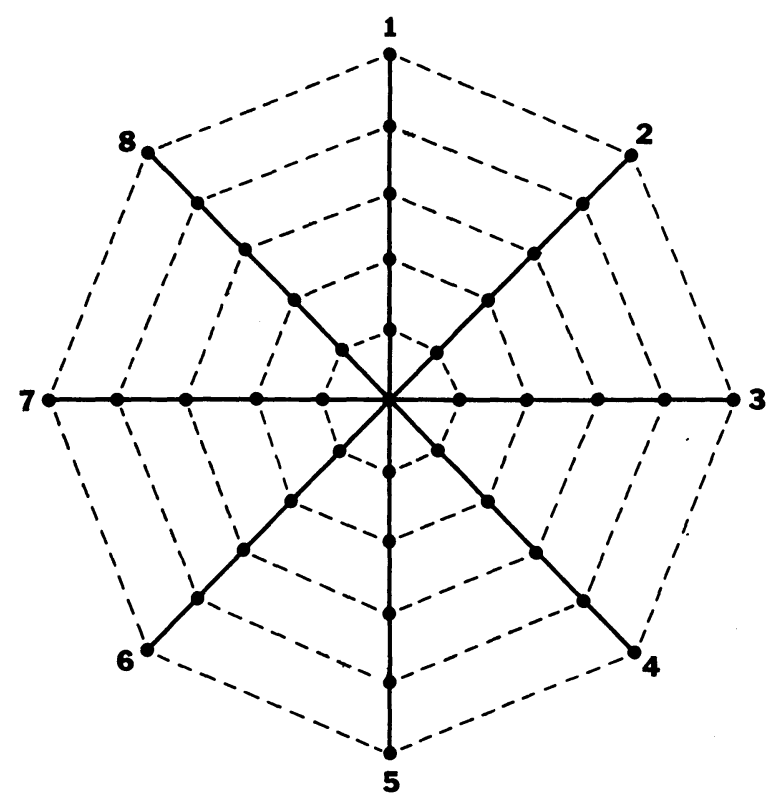

Figure 1. Grid, showing the 40 locations (black dots) where the displaced target letter could appear in the perceptual extent experiment.
10 times. The target letters were randomly assigned to the 40 axis by distance combinations.

Each speed-reader (hereafter called $L$ and $R$ ) received three sessions of 80 trials each, with each session separated by 3-5 days. The five control subjects, undergraduates from an introductory psychology course with normal vision, received a single session.

Materials and Apparatus. The displaced (target) letters were uppercase 18-point Franklin Gothic font. The masking field consisted of jumbled lines and angles and covered the entire visual field. A card containing the eight target letters and a grid, showing the 40 locations, were available throughout the experimental session. The letters on the available card were ordered alphabetically and were in the same font as the letters on the experimental trials. All stimuli were presented by an Iconix four-field tachistoscope (Model 6137-4).

\section{Paragraph Perception}

Materials and Apparatus. A total of six different text selections were used, three from paperback novels and three from introductory psychology texts. A page was arbitrarily chosen from each text, and about 180 consecutive words defined a selection. Each selection was typed in uppercase with an IBM Selectric typewriter and affixed to a stimulus card. The selection always contained 20 lines of text and measured about $4 \mathrm{in}$. in the horizontal and $4.5 \mathrm{in}$. in the vertical.

Procedure. The subject was told that text-like material would be briefly shown, and that the task was to identify as many words as possible on a subsequent recognition test. On each trial, a fixation point appeared $(1,000 \mathrm{msec})$, followed by the selection $(200,500$, or $800 \mathrm{msec})$, and terminated by a masking field $(500 \mathrm{msec})$. The fixation point was centered in the middle of the passage. Following presentation of a passage, the subject was given a sheet containing 18-24 words and was told to mark any word that had appeared in the selection. The subject was aware that only some of the words on the recognition test had, in fact, appeared in the selection. Actually, about $50 \%$ of the words were foils. Only content words were used, and they were semirandomly chosen from the selection. The only restrictions were that only content words could appear on the recognition test, with the words uniformly sampled from the 20 lines.

The subject was allowed to dark adapt for about $5 \mathrm{~min}$, and a couple of practice trials were given with one of the six passages. A total of 30 experimental trials followed, determined by three exposure durations $(200,500,800 \mathrm{msec})$, five passages, and two replications. The 30 trials were randomized across durations, passage type, and replications. Each subject received a single session. The control subjects were six introductory psychology students, none of whom had participated in the perceptual extent task. All trials were presented by the Iconix tachistoscope.

\section{Text Comprehension}

Procedure. The speed-readers were informed that they would be given a nontechnical text on human memory and would then take a multiple-choice test over the content. The subject was handed the Klatzky (1975) text and given about $10 \mathrm{sec}$ to quickly peruse the text, so as to note the font, number of figures, and so on. Two markers in the text indicated the starting and ending locations to be read; the initial marker indicated the first content chapter, and the last marker preceded the reference section. The subject understood that the exam would cover the material between the two markers.

When the subject was ready, the experimenter noted the time on a watch and gave the signal to begin. After completing the text, the subject was given about $30 \mathrm{sec}$ to rest and then was handed the multiple-choice test. The test contained 20 questions, each with four alternatives. The subject was told that none, all, or some of the alternatives might be correct, and that each alternative should be carefully considered before marking it true. No time demands were made on answering the test.

Each speed-reader received two additional opportunities to 
read the Klatzky (1975) text and to take the identical test. All three sessions were separated by 3-5 days each, and only the ordering of the questions was changed from one test to the next.

\section{RESULTS}

\section{Perceptual Extent}

Figure 2 shows the mean identification accuracy for the two speed-readers (left panel), as a function of distance from the fixation point; comparable data for the control subjects are shown in the right panel.

The overall accuracy rate was .633 for the speedreaders and .678 for the control subjects $(p>.20)$. Both groups showed similar performance decrements with increasing distance of the displaced letter from the fixation point. This is readily seen by inspection of the left panel of Figure 2, which shows the mean performance of the control subjects.

\section{Paragraph Perception}

For each subject, hits and false alarms were noted for each trial and then averaged across selections. Since increases in exposure duration $(200,500,800 \mathrm{msec})$ resulted in slight increases in accuracy, performance was also averaged across exposure durations. Table 1 shows the probability of hits and false alarms for the six control subjects and the two speed-readers; also shown are two correction measures, a high-threshold correction for guessing $\left(\mathrm{p}^{\prime}\right)$ and a signal detection measure of sensitivity (d') (Green \& Swets, 1966).

On the average, the hit and false alarm rates were higher for the speed-readers, but both correction measures suggested that both groups had comparable levels of sensitivity in identifying words from the selections.

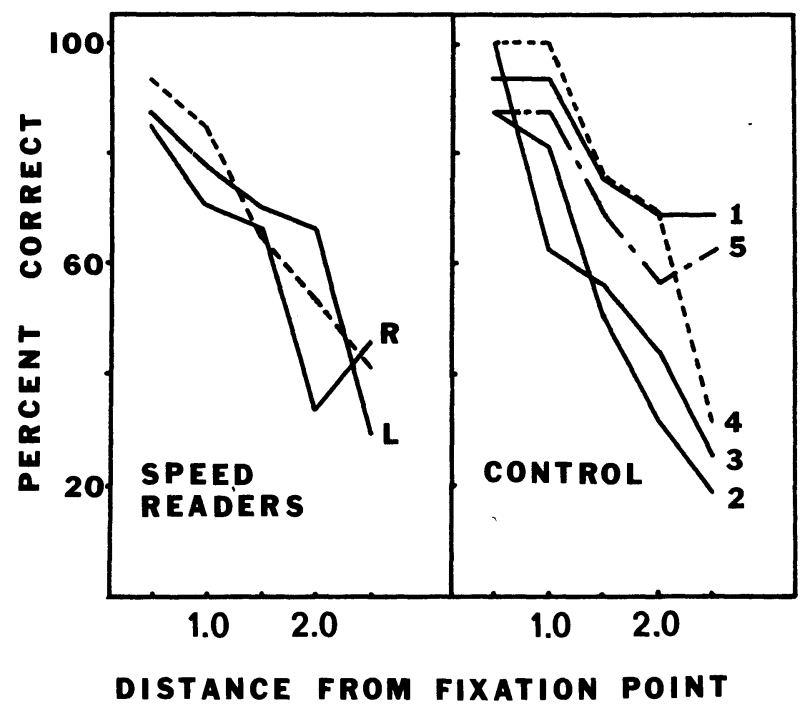

Figure 2. Mean percentage correct, as a function of distance of the displaced letter from the fixation point (Speed-Readers $\mathbf{R}$ and $L$ in left panel; individual control subjects in right panel; average performance of control subjects shown as dotted line in left panel).
Table 1

Performance on Paragraph Perception Task

\begin{tabular}{lcccr}
\hline & $\mathrm{P}(\mathrm{H})$ & $\mathrm{P}(\mathrm{FA})$ & $\mathrm{p}^{\prime}$ & \multicolumn{1}{c}{$\mathrm{d}^{\prime}$} \\
\hline & \multicolumn{4}{c}{ Controls } \\
1 & .068 & .012 & .057 & .59 \\
2 & .019 & .006 & .013 & .43 \\
3 & .071 & .015 & .057 & .70 \\
4 & .015 & .024 & -.009 & -.19 \\
5 & .068 & .045 & .024 & .21 \\
6 & .059 & .009 & .050 & .81 \\
Mean & .050 & .018 & .032 & .42 \\
& & Speed-Readers & & \\
$\mathrm{R}$ & .096 & .048 & .050 & .36 \\
$\mathrm{~L}$ & .194 & .152 & .050 & .17 \\
Mean & .145 & .100 & .050 & .26 \\
\hline
\end{tabular}

Table 2

Text Comprehension Performance for Speed-Readers and Class

\begin{tabular}{cccc}
\hline & Score & Grade & Frequency \\
\hline \multicolumn{3}{c}{ Class } & \\
& $0-14$ & F & 10 \\
& $15-25$ & D & 7 \\
& $26-40$ & C & 15 \\
& $41-49$ & B & 10 \\
$50-$ & A & 10 \\
R & 12 & Speed-Readers & \\
L & 10 & F \\
\hline
\end{tabular}

On the average, control subjects checked an average of .74 words on each test; the two speed-readers checked an average of 2.67 words/test. Of the words checked as old, the control subjects were correct $72 \%$ of the time; for the speed-readers, $59 \%$ of the checked words were correct (chance is $50 \%$ ).

\section{Text Comprehension}

On the average, Speed-Reader $\mathrm{L}$ took between 1.5 and $3.0 \mathrm{~min}$ to read the text, which averages to about 30,000 wpm; Speed-Reader $R$ required between 3.0 and $5.5 \mathrm{~min}$, which averages to about $15,000 \mathrm{wpm}$.

Since the comprehension test consisted of 20 multiplechoice questions, each with four alternatives, scores could range from -80 to +80 . Leaving the entire exam blank would result in a score around 0 . Table 2 shows the frequency distribution of exam scores on the multiplechoice exam by students enrolled in the human memory course, and the grades assigned for this part of the exam. For example, students scoring +14 or less received a grade of $F$ (flunk), whereas students with a score of +50 or above received a letter grade of A. Also shown in Table 2 is the mean performance of the two speedreaders. Overall, both speed-readers would have failed the exam: $R$ received successive scores of $+8,+18$, and +10 , on the first, second, and third reading, respectively; $L$ received corresponding scores of $+4,+16$, and +10 . 


\section{CONCLUSION}

Neither speed-reader demonstrated exceptional skills on the three tasks: Their perceptual extent was no different from control subjects. Their accuracy on the paragraph perception test was comparable to that of control subjects, although they demonstrated a much greater tendency to guess at the words presented. And both speed-readers would have failed the college exam. In fact, there is little reason to believe that either speedreader would ever pass the exam, since neither reader exhibited improvement with successive readings.

In conclusion, the only noteworthy skill exhibited by the two speed-readers was a remarkable dexterity in page-turning.

\section{REFERENCES}

Gibson, E. J., \& Levin, H. The psychology of reading. Cambridge, Mass: M.I.T. Press, 1975.
Green, D. M., \& Swets, J. A. Signal detection theory and psychophysics. New York: Wiley, 1966.

HABER, R., \& Hershenson, M. The psychology of visual perception. New York: Holt, Rinehart, \& Winston, 1980.

Klatzky, R. L. Human memory. San Francisco: Freeman, 1975. REed, S. K. Cognition. Monterey, Calif: Brooks/Cole, 1982.

\section{NOTES}

1. The American Speedreading Academy was the dominant speed-reading program at Arizona State University, with offices located in the southwest, primarily Arizona and southern California. Obviously, results of the present study cannot be generalized to other speed-reading programs.

2. The human memory course at Arizona State University is primarily taken by sophomores and juniors, with many of the students nonpsychology majors. Most students, however, had had courses in introductory and experimental psychology.

(Received for publication February 9, 1983.) 